\title{
A biodiverse housing market in hermit crabs: proposal for a new biodiversity index
}

\author{
Mark E. Laidre ${ }^{1}$ and Geerat J. Vermeij ${ }^{2}$ \\ 'Department of Integrative Biology, University of California, Berkeley, USA; mlaidre@berkeley.edu \\ 2Department of Geology, University of California, Davis, USA; gjvermeij@ucdavis.edu
}

Received 9-V-2012 Corrected 3-VII-2012 Accepted 6-VIII-2012

\begin{abstract}
Quantifying variation in biodiversity is an important goal of biology. However, because inventorying biodiversity, especially marine biodiversity, is costly, difficult, and time consuming, there is great value in simple metrics that can reliably indicate a given region's biodiversity and that can be efficiently gathered. We inventoried shells used as portable houses by terrestrial hermit crabs (Coenobita compressus) in Osa Peninsula, Costa Rica, a biodiversity hotspot. Forty-one species were recorded, the largest number registered for any hermit crab population. We propose that housing market diversity in hermit crabs might provide a convenient biodiversity index of ecosystems, potentially facilitating comparisons across different sites.
\end{abstract}

\section{KEY WORDS}

Biodiversity inventory, species richness, Costa Rica, Osa Peninsula, gastropods, shells, homes, hermit crabs, Coenobita compressus.

\section{RESUMEN}

Cuantificar la variación de la biodiversidad es un objetivo importante de la biología. Sin embargo, debido a que tales inventarios, en especial para la biodiversidad marina, son costosos, difíciles y consumen mucho tiempo, hay un gran valor en indicadores simples que permitan determinar la biodiversidad de una región determinada de manera eficiente. Hicimos un inventario de las conchas usadas como casas móviles terrestres por los cangrejos ermitaños (Coenobita compressus) en la Península de Osa, Costa Rica, un "punto álgido" de biodiversidad. Se registraron 41 especies, el mayor número registrado en cualquier población de cangrejos ermitaños. Proponemos que la "diversidad del mercado de vivienda" en los cangrejos ermitaños puede proporcionar un índice de biodiversidad ecosistémica conveniente, lo que podría facilitar las comparaciones entre sitios.

\section{PALABRAS CLAVE}

Inventarios de biodiversidad, riqueza de species, Costa Rica, Península de Osa, gasterópodos, conchas, casas, cangrejo ermitaño, Coenobita compressus.
Biodiversity, a measure of the diversity of species in a given area, is deeply connected to the functioning and productivity of ecosystems and ultimately to the welfare of the human species (Ehrlich \& Wilson 1991, Solan et al. 2006). Levels of biodiversity vary dramatically around the world, with some regions, especially in the tropics, accounting for a disproportionate amount of earth's species (Forsyth \& Miyata 1984). Quantifying such global variation in biodiversity is an important goal of biology and is vital to channeling conservation efforts effectively (Wilson 1999). However, because inventorying biodiversity, especially marine biodiversity, is costly, difficult, and time consuming (Vargas \& Cortés 2006, Solan et al. 2009), there is great value in simple metrics that can reliably indicate a given region's biodiversity and that can be efficiently gathered (Wilson 1999).

Here, we consider how "housing diversity" in terrestrial hermit crabs (Coenobita spp.) can function as a convenient biodiversity index, melding biodiversity data from whole ecosystems into a single, readily obtainable measure. Terrestrial hermit crabs roam beaches around the world and constitute a substantial portion of the above-ground biomass at the land-ocean interface (Greenaway 2003, Laidre 2012a). The natural history of these crabs entails obligately carrying portable houses in the form of gastropod shells (Vermeij 1993, Laidre 2007). These houses can be readily 
sampled by researchers while crabs forage and socialize on the beach (Laidre 2010). The diversity of hermit crab "housing markets" could potentially be used to gauge overall aspects of ecosystem functioning and productivity in an analogous fashion to how economists use various measures of our own species' housing market to infer the productivity and health of the economy (see Vermeij \& Leigh 2011 on the parallels between ecosystems and economies). Indeed, in the case of the hermit crab housing market, there is a direct link between the diversity of shells that crabs inhabit and the biodiversity of the surrounding marine and terrestrial ecosystems. This is because the marine ecosystem supplies the crabs' houses through the mortality schedules of gastropod species that thrive in the ocean (Laidre 2011); and because both the marine and the terrestrial ecosystem supply the crabs' food through the variety of plants and animals that support the crabs' omnivorous diet (Thacker 1996, Laidre 2012b).

As a first step toward examining the potential utility of hermit crab shell diversity as a biodiversity index we sampled the species of shells inhabited by $C$. compressus hermit crabs in the Osa Peninsula of Costa Rica. The Osa is regarded as one of the key marine and terrestrial biodiversity hotspots of the world, boasting over 250,000 species and referred to as a "crown jewel" of biodiversity by E.O. Wilson (Toft \& Larsen 2009, Wilson quoted therein).

\section{METHODOLOGY}

To inventory shell diversity in the Osa hermit crab population, one of us (M.E.L.) conducted transects along a $<5 \mathrm{~km}$ stretch of beach that was bordered by two rivers, the Rio Piro to the North $\left(08^{\circ} 23^{\prime} 744^{\prime \prime} \mathrm{N}, 083^{\circ} 20^{\prime} 323^{\prime \prime} \mathrm{W}\right)$ and the Rio Los Sambos to the South $\left(08^{\circ} 23^{\prime} 227^{\prime \prime} N, 083^{\circ} 19^{\prime} 135^{\prime \prime}\right.$ W). M.E.L. walked this transect back-and-forth daily during March and April 2011, scanning for shells worn by hermit crabs at the edge of the beach-forest interface. Transects usually began shortly after sunrise (0500), a time of peak foraging activity for the crabs. Depending on the tides each transect could result in encounters with fewer than 100 hermit crabs or many orders of magnitude more. During the transects any shells inhabited by hermit crabs that exhibited a distinctive morphology, potentially constituting a unique shell species, were collected. Generally, five or more specimens of each potential shell species were obtained. Some shell species (e.g., Nerita scabricosta) appeared more common than others, but this study did not attempt to quantify the relative abundance of different species. Rather, the objective was solely to inventory the set of shell species used by the hermit crabs. All shell specimens that were collected were taken back to the US where the second author identified them.

\section{RESULTS}

\section{Osa inventory}

Our inventory of shells in the Osa hermit crab population yielded a total of 41 species (Table 1), 36 of which derived from marine habitat, 4 of which derived from freshwater habitat, and 1 of which derived from terrestrial habitat. The vast majority of shells inhabited by crabs ( 40 of 41) were gastropod shells (Fig. 1A), but crabs were also occasionally found in palm nut shells (Fig. 1B) that originated on land. Rarely, crabs were also found in artificial human-derived objects (e.g., parts of bottles; A. Zolei, personal communication; Laidre personal observation; Fig. 1C); though such objects were not included as 'species' in our inventory. The gastropod shells the crabs occupied were often highly degraded: the sculpture was typically eroded, and in a process that is not well understood, the crabs had also worn away the columella and internal structure of their shells (cf. Abrams 1978, Laidre 2012a). Exemplar pictures of all identified shell species are available upon request from the first author and specimens are also being archived in the University of California Museum of Paleontology (UCMP, located in Berkeley, CA), which houses remains of both fossil and modern organisms.

\section{Comparisons with the literature}

To determine how our inventory of Osa hermit crab shell diversity compared with studies of other hermit crab populations we examined the shell diversity catalogued in prior hermit crab studies in the literature (reviewed in Hazlett 1981, Barnes 2003). To our knowledge, the Osa inventory represents the most diverse set of shell species ever recorded for any population of hermit crabs. On average, other studies reported 16,7 $\pm 1,7$ (Mean \pm SE) shell species in the hermit crab populations they examined $(\mathrm{N}=27)$, with the second greatest shell diversity after our study being 34 species, which was reported in a population of marine hermit crabs (Calcinus obscurus) in Panama (Abrams 1980; cf. compilations in Hazlett 1981, Barnes 2003).

Notably, many of the studies we surveyed in the literature involved collections of hermit crab shells across much greater geographical ranges than our own, with the ranges often encompassing several separated populations or several sympatric hermit crab species, all of whose shells were grouped together. Such a 'lumping' approach should, if anything, have increased the shell diversity found in these studies relative to our own, since in our study we conservatively sampled but a small portion of the range of the single terrestrial hermit crab species present in the Osa. If our sampling were extended across an even 


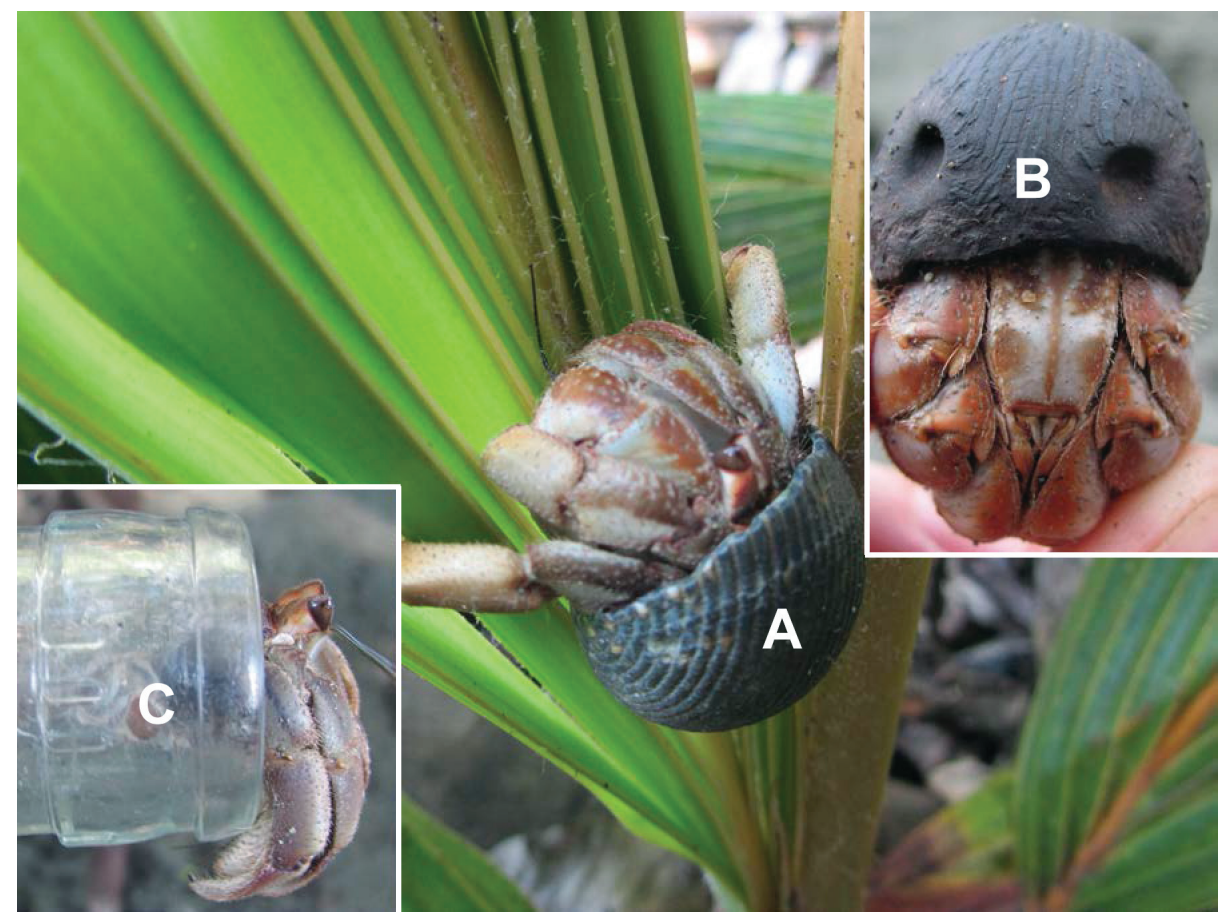

FIG. 1. Pictures of terrestrial hermit crabs (Coenobita compressus) from the Osa Peninsula of Costa Rica occupying (A) a marine gastropod shell (Nerita scabricosta), (B) a terrestrial palm nut shell, and $(C)$ an artificial bottle shell. All photos by the first author.

\section{TABLE 1}

Inventory of species of shells ${ }^{\mathrm{a}}$ occupied by terrestrial hermit crabs (Coenobita compressus) in the Osa Peninsula of Costa Rica along a $<5 \mathrm{~km}$ strip of beach.

Marine
Nerita scabricosta (Lamarck)
Nerita funiculata (Menke)
Littoraria zebra (Donovan)
Turbo saxosus (Wood)
Vasula melones (Duclos)
Acanthais brevidentata (Wood)
Opeatostoma pseudodon (Burrow)
Stramonita biserialis (Blainville)
Gemophos ringens (Reeve)
Bursa corrugata (Perry)
Neorapana muricata (Broderip)
Thais triangularis (Blainville)
Thais speciosa (Valenciennes)
Plicopurpura columellaris (Lamarck)
Leucozonia cerata (Wood)

\section{Marine}

Cymia tectum (Wood)

Naticarius sp.

Polinices sp.

Semicassis centiquadrata (Valenciennes)

Malea ringens (Swainson)

Supplanaxis planicostatus (Sowerby)

Thericium adustum (Kiener)

Thericium menkei (Carpenter)

Agathistoma verrucosa (McLean)

Agathistoma panamensis (Phillippi)

Bulla punctulata (A. Adams)

Echinolittorina conspersa (Phillippi)

Macrocypraea cervinetta (Kiener)

Pseudozonaria arabicula (Lamarck)

Pseudozonaria robertsi (Hidalgo)

\author{
Marine \\ Monoplex wigmanni (Anton) \\ Conus patricius (Hindes) \\ Conus nux (Broderip)
}

Species 34 - different from all others ${ }^{\mathbf{b}}$ Species 35 - different from all others ${ }^{\mathbf{b}}$ Bifurcium bicanalifera (G.B. Sowerby)

\section{Freshwater}

Pomacea sp.

Clypeolum latissimum (Broderip) Species 39 - different from all others ${ }^{b}$ Species 40 - different from all others ${ }^{b}$

\section{Terrestrial}

Palm nut ${ }^{c}$

a Note that for gastropod shells, some species referred to here can be found in Keen (1971), while others are based on updated and revised taxonomic categorizations distributed throughout the literature since Keen's comprehensive review.

b Formal identification for these four species was impossible since all the specimens that represented each of these species were substantially degraded. However, it was clear that each of these species was different from one another and also different from all the other species that were identified. Pictures are available upon request.

c The palm nut shells that crabs occupied may have come from multiple tree species, but since these shells were too degraded to identify, we conservatively classified all palm nut shells as representing a single species. 
broader range of the Osa, additional shell species might also be found. For instance, further north, in Corcovado National Park, still within the Osa Peninsula, C. compressus has been observed using fossil shells ( $T$. Larsen, personal communication), and many shells that hermit crabs inhabit in the Osa may have yet to be inventoried.

\section{DISCUSSION}

We suggest that the large number of shell species in the Osa hermit crab population is interesting not just in documenting the rich biodiversity of the Osa region (Toft \& Larsen 2009), but that it may also be relevant more broadly in motivating the use of hermit crab shell diversity as a possible biodiversity index for comparing different sites around the globe. The idea that shell diversity in hermit crabs could be used to compare biodiversity between different regions has not been widely considered. Indeed, much of the literature we surveyed on hermit crab shell diversity only noted the shell species that crabs inhabited as an incidental part of the main study (though see Barnes 2003 for an exception). In general, these prior studies provided few if any details on the methods by which shell species were inventoried (e.g., whether inventorying involved transects, involved collecting a certain threshold number of crabs, or how exactly the transects or collections were carried out). It is well established that methodological differences in inventorying biodiversity can limit the potential for comparison between studies (Gotelli \& Colwell 2001), and such methodological differences may partly explain some of the variation in shell diversity recorded across prior hermit crab studies. However, we propose that once sampling procedures are controlled and standardized, future studies of hermit crab shell diversity could provide both a useful and a highly convenient way of comparing biodiversity across different sites. What advantages would hermit crab shell diversity provide as a biodiversity index and what would this index ultimately reflect?

For terrestrial hermit crabs like C. compressus, population abundances and shell diversity are intimately linked to both terrestrial and aquatic ecosystems. More productive and diverse terrestrial ecosystems ultimately yield bigger crab populations, since the many plant and animal species the crabs critically rely upon for food are often terrestrially-derived (Laidre 2012b). Similarly, more productive and diverse aquatic ecosystems yield both bigger crab populations as well as a greater diversity of shell species within these populations, since the objects the crabs require as houses are overwhelming aquatically-derived, from either marine or freshwater ecosystems
(Hazlett 1981). C. compressus and other Coenobita species can therefore provide a practical, combined measure of both marine and terrestrial biodiversity, which could be valuable given that biodiversity inventorying is sometimes restricted to single ecosystems or select portions of ecosystems due to the time constraints and monetary costs of surveying (Stergiou \& Browman 2005, Solan et al. 2009). Another valuable aspect of using hermit crab shell diversity as a biodiversity index is that many of the aquatic gastropods - whose shells crabs use as houses - live in subtidal and intertidal regions that can be difficult or dangerous to access. In contrast, secondarily sampling the remnant gastropod shells in the crab population is far more feasible, since the crabs roam the land where they are readily visible and easily collected (Laidre 2010). Lastly, many hermit crab species have extensive ranges ( $C$. compressus, for example, extends from lower California to Chile; Bright 1966), so biodiversity comparisons can be made using this index across widely separated regions with the very same hermit crab species.

While hermit crab shell diversity could be extremely useful as a biodiversity index, there are also no doubt some limitations and cautions. First and foremost, it would be important to apply the index to a wide range of local areas of known biodiversity, spanning depauperate to rich, to gauge how well the measures in fact correlate with established levels of biodiversity. On a global scale, Barnes (2003) has shown in a literature survey that, in two hermit crab genera, shell diversity peaks in the tropics and decreases toward the poles. But more data from specific regions with established biodiversity levels would be informative. The Osa region, an area known for its incredible biodiversity (Toft \& Larsen 2009), proved in the current study to contain the greatest shell diversity of any hermit crab population sampled thus far, but many additional sites of extreme biodiversity have had little if any sampling of shell diversity in their hermit crabs and so could profitably be inventoried to test our proposal. One important limitation that might be raised about applying hermit crab shell diversity as a biodiversity index is that hermit crabs may prefer certain shell species over others (Hazlett 1981), thus potentially biasing the index. However, in terrestrial hermit crabs, even though there is a clear hierarchy of shell preferences when crabs are given the opportunity to choose in the laboratory, these preferences are eroded in the field by the extremely limited availability of shells (Abrams 1978). Indeed, during the transects undertaken for this study the few unoccupied gastropod shells that were found had rocks or other blockages in them that prevented hermit crab entry (Laidre, personal observation). And the very fact that crabs could be found in artificial non-shell objects (Fig. 1C), objects which could 
only poorly accommodate the crabs' asymmetrical abdomens, indicates that individuals are desperate enough to inhabit any available shell, even sub-optimal proxies (cf. Barnes 2002 on plastic debris). Thus, as more studies with systematic methodology accumulate on shell diversity in hermit crab housing markets around the world, it may become possible to apply such inventories more widely as a biodiversity index to measure the diversity of ecosystems.

\section{ACKNOWLEGEMENTS}

We thank the nonprofit conservation organization 'Osa Conservation' for making this research possible. Supported by the Miller Institute for Basic Research in Science.

\section{REFERENCES}

Abrams, P. 1978. Shell selection and utilization in a terrestrial hermit crab, Coenobita compressus (H. Milne Edwards). Oecologia 34: 239-253.

Abrams, P.A. 1980. Resource partitioning and interspecific competition in a tropical hermit crab community. Oecologia 46: 365-379.

Barnes, D.K.A. 2002. Biodiversity: invasions by marine life on plastic debris. Nature 416: 808-809.

Barnes, D.K.A. 2003. Local, regional and global patterns of resource use in ecology: hermit crabs and gastropod shells as an example. Mar. Ecol. Prog. Ser. 246: 211-223.

Bright, D.B. 1966. The land crabs of Costa Rica. Revista Biología Tropical 14: 183-203.

Ehrlich, P.R. \& E.O. Wilson. 1991. Biodiversity studies: science and policy. Science 253: 758-762.

Forsyth, A. \& K. Miyata. 1984. Tropical nature: life and death in the rain forests of Central and South America. Simon and Schuster, New York, USA.

Gotelli, N.J. \& R.K. Colwell. 2001. Quantifying biodiversity: procedures and pitfalls in the measurement and comparison of species richness. Ecol. Lett. 4: 379-391.

Greenaway, P. 2003. Terrestrial adaptations in the Anomura (Crustacea: Decapoda). Mem. Mus. Vict. 60: 13-26.
Hazlett, B.A. 1981. The behavioral ecology of hermit crabs. Ann. Rev. Ecol. Syst. 12: 1-22.

Keen, A.M. 1971. Sea shells of tropical west America: marine moIlusks from Baja California to Peru. Stanford University, Stanford, California, USA.

Laidre, M.E. 2007. Vulnerability and reliable signaling in conflicts between hermit crabs. Behav. Ecol. 18: 736-741.

Laidre, M.E. 2010. How rugged individualists enable one another to find food and shelter: field experiments with tropical hermit crabs. Proc. Roy. Soc. Lond. B 277: 1361-1369.

Laidre, M.E. 2011. Ecological relations between hermit crabs and their shell-supplying gastropods: constrained consumers. J Exp Mar Biol Ecol 397: 65-70.

Laidre, M.E. 2012a. Homes for hermits: temporal, spatial, and structural dynamics as transportable homes are incorporated into a population. J. Zool. 288: 33-40.

Laidre, M.E. 2012b, in press. Foraging across ecosystems: diet diversity and social foraging spanning aquatic and terrestrial ecosystems by an invertebrate. Mar Ecol: 1-10.

Solan, M., D.G. Raffaelli, D.M. Paterson, P.C.L. White \& G.J. Pierce. 2006. Marine biodiversity and ecosystem function: empirical approaches and future research needs. Mar Ecol Prog Ser 311: 175-309.

Solan, M., P. van Avesaath, H. Hummel \& C. Heip. 2009. Marine biodiversity: current understanding and future research. Mar Ecol Prog Ser 396: 165-306.

Stergiou, K. \& H. Browman. 2005. Bridging the gap between aquatic and terrestrial ecology. Mar Ecol Prog Ser 304: 271-307.

Thacker, R.W. 1996. Food choices of land hermit crabs (Coenobita compressus H. Milne Edwards) depend on past experience. J Exp Mar Biol Ecol 199: 179-191.

Toft, R. \& T. Larsen. 2009. Osa: where the rainforest meets the sea. Zona Tropical, China.

Vargas, R. \& J. Cortés. 2006. Biodiversidad marina de Costa Rica: Crustacea: Infraorden Anomura. Revista de Biología Tropical 54: 461-488.

Vermeij, G.J. 1993. A natural history of shells. Princeton University, Princeton, New Jersey, USA.

Vermeij, G.J. \& E.G. Leigh. 2011. Natural and human economies compared. Ecosphere 2: article 39.

Wilson, E.O. 1999. The diversity of life. W.W. Norton, New York, USA. 